\title{
Rotatividade nos cargos de confiança da administração federal brasileira (1999-2013)
}

Felix Lopez

Instituto de Pesquisa Econômica Aplicada (Ipea)

Maurício Bugarin

Universidade de Brasília (UnB)

Karina Bugarin

Economics and Politics Research Group (EPRG, UnB/CNPq)

Este texto apresenta e analisa dados sobre a ocupação e rotatividade dos cargos DAS da administração federal brasileira, de 1999 a 2013, em particular as diferenças observadas entre governos, entre áreas de políticas públicas e entre níveis hierárquicos. Para tanto, analisamos as informações de uma base original construída a partir de informações do sistema integrado de administração de recursos humanos da administração federal (Siape). Mostramos que: a) a rotatividade tem momentos de pico, que são os primeiros anos de governo dos presidentes, ao que se sucede uma tendência ao decréscimo nas taxas; b) os cargos mais altos na hierarquia sofrem maior rotatividade, o que contraria a noção préconcebida segundo a qual os cargos de menor hierarquia, por serem mais sujeitos à troca política e distribuição personalista, teriam rotatividade mais intensa; c) se observa maior rotatividade entre os ocupantes de cargos de DAS que não pertencem à carreira do serviço público. Por fim, mostramos haver; d) tendência de rotatividade menor em ministérios responsáveis pela política econômica do governo, se comparados aos ministérios responsáveis pelas políticas sociais.

Palavras-chave: administração federal, burocracia, cargo em comissão, rotatividade

Artigo recebido em fevereiro de 2014. Versão final em outubro de 2014. 


\section{Rotación en los cargos de confianza de la administración federal brasileña (1999-2013)}

Este texto presenta y analiza datos sobre la ocupación y rotación de cargos DAS de la administración federal brasileña, entre 1999 y 2013, en particular las diferencias observadas entre los gobiernos, entre áreas de políticas públicas y entre niveles jerárquicos. Por tanto, analizamos las informaciones de una base original construida a partir de informaciones del sistema integrada de administración de los recursos humanos de la administración federal (SIAPE). Demostramos que: a) la rotación de cargos tiene momentos pico, que son los primeros años del gobierno de los presidentes, que siguieron una tendencia a la disminución de las tasas; b) que los cargos más altos en la jerarquía sufren una mayor rotación, lo que contradice la idea preconcebida de que los cargos de menor jerarquía, que están más sujetos a intercambio político y la distribución personalista, tendrían una rotación más intensa; c) que se observa una mayor rotación entre los ocupantes de cargos de DAS que no pertenecen a uma carrera en el servicio civil. Por fin, demostramos que hay d) menor tendencia de rotación de cargos en las áreas técnicas, en comparación con las áreas sociales.

Palabras clave: administración federal brasileña, burocracia, nombramientos políticos, rotación de cargos públicos

\section{Turnover rates for higher management posts in the Brazilian federal civil service from 1999 to 2013}

This paper presents and analyzes data on appointments and turnover rates for higher management posts, the DAS posts, in the Brazilian federal civil service from 1999 to 2012. We focus on differences among governments, policy areas and DAS hierarchical levels. In order to do so, we explore information from a unique database from the federal administration's human resources management system (SIAPE). Our results show that: a) turnover rates peak during the first years of a president's term, and then decrease in subsequent years, b) turnover is higher at the top management posts, which contradicts the preconceived notion that posts of lower ranks, being more susceptible to political exchanges and personalistic appointments, would show more intense turnover rates; c) that DAS officeholders coming from the private sector are subject to higher turnover rates than those coming from public service careers. Finally, we show that d) turnover in economic policy ministries, such as the Finance Ministry, is lower than in the social policy ministries, such as the Health Ministry.

Keywords: Brazilian federal public administration, bureaucracy, political appointments, turnover 


\section{Introdução}

A ocupação dos cargos de confiança é um dos aspectos mais importantes e menos explorados do sistema político e administrativo brasileiro. Essa importância decorre da centralidade que as nomeações assumem para o processo de formação e gerência das coalizões de governo e porque os nomeados são responsáveis por desenhar e executar parte expressiva das políticas públicas do País. Os cargos de confiança, e em particular a rotatividade das nomeações, são também uma via inicial para abordar diferentes questões concernentes à gestão pública e ao sistema político: quais os seus efeitos sobre o desenho e a capacidade de implantação de policies; qual a relação das nomeações com a atuação dos grupos de pressão em diferentes jurisdições; que cargos estão mais sujeitos às influências políticopartidárias e por que, são algumas das questões de análise possíveis. As respostas demandam uma compreensão prévia do cenário da ocupação e rotatividade dos cargos federais, que é o principal objetivo deste texto.

Apresentamos, de forma detalhada, dados sobre ocupação e rotatividade, por áreas de governo e níveis dos cargos, em um período que recobre 14 anos (19992013), iniciando nos três últimos anos do segundo Governo Cardoso, passando por dois Governos Lula, até os três primeiros anos do Governo Rousseff. ${ }^{1}$ A análise é feita a partir de uma base inédita sobre rotatividade que cumpre, a nosso ver, a função primordial de lançar algumas luzes sobre um tema ainda pouco analisado. ${ }^{2}$

O texto se estrutura da seguinte forma. A próxima seção apresenta a estrutura dos cargos de confiança da administração federal, o conceito de rotatividade empregado e a forma como os dados foram construídos. A terceira e a quarta seções descrevem e analisam as taxas de rotatividade na administração federal e suas variações em diferentes órgãos governamentais, utilizando diferentes níveis de agregação. A seção conclusiva resume o argumento e sugere uma agenda de pesquisa sobre a relação entre política e burocracia com base na abordagem baseada em variações na rotatividade.

\footnotetext{
${ }^{1}$ De acordo com os gestores da Secretaria de Gestão Pública (Segep) do Ministério do Planejamento, Orçamento e Gestão (MP) responsáveis por gerir a base Siape, 1999 é o primeiro ano em que há disponibilidade de dados confiáveis sobre quadro de pessoal da administração pública federal.

${ }^{2}$ Exceto pelo texto de Praça et al. 2012.
} 


\section{Estrutura dos cargos}

A estrutura de cargos da administração federal divide-se entre os cargos efetivos e cargos em comissão. Os cargos efetivos, em regra, são ocupados por servidores de carreira, mediante aprovação em concurso público. Os cargos em comissão são de livre provimento, ou seja, livre nomeação e exoneração de funcionários, sejam eles de carreira ou de fora do serviço público. Os cargos em comissão dividem-se em quatro categorias principais:

a) cargos de livre provimento das agências reguladoras (Lei no 9986/2000);

b) cargos de direção das instituições federais de ensino superior;

c) cargos de natureza especial (CNEs);

d) cargos de direção e assessoramento superior (DAS).

A Tabela 1 resume os tipos de cargos em comissão e as respectivas atribuições. O grupo de cargos de direção e assessoramento superiores, DAS, tem o encargo de planejar, supervisionar, coordenar e controlar atividades, nos mais altos níveis da hierarquia dos órgãos federais da administração direta e autárquica. Seus ocupantes são responsáveis por grande parte da formulação de programas, normas e critérios que deverão ser observados pelos demais escalões. (QUEIROz, 2009)

Os cargos de direção e assessoramento superiores (DAS) dividem-se em duas categorias: cargo de direção superior (DAS 101) e cargo de assessoramento superior (DAS 102), cada um dos quais em seis níveis hierárquicos (DAS 1 a 6). Nossos dados tratam exclusivamente dos cargos DAS, em todos os níveis. ${ }^{3}$

\section{Metodologia, base de dados e critérios de mensuração da rotatividade}

A base de dados utilizada nesta pesquisa inclui a situação funcional detalhada de cada funcionário que estava, ou esteve, empregado ocupando cargo de DAS no mês de dezembro de cada ano, de 1999 a 2013, e foi construída a partir do sistema que gerencia informações sobre o funcionalismo público federal, o Siape. ${ }^{4}$

\footnotetext{
${ }^{3}$ Para uma análise detalhada sobre a evolução histórica das regras que presidem a ocupação dos cargos de livre nomeação, ver Lameirão (2011).

${ }^{4}$ Somos gratos à colaboração dos servidores da Secretaria de Gestão Pública do Ministério do Planejamento, Orçamento e Gestão (Segep/MP): Edi Maciel, Paulo Caserta Vasconcellos, Glória Nunes e Márcio Silva.
} 


\section{Tabela 1: Atribuições dos cargos da administração pública}

\begin{tabular}{|c|c|c|}
\hline $\begin{array}{l}\text { Cargos - } \\
\text { hierarquia e } \\
\text { natureza }\end{array}$ & Ocupantes & Atribuições e competência \\
\hline Político & $\begin{array}{l}\text { Ministro de Estado, secretário } \\
\text { especial ou chefe de órgão essencial } \\
\text { à Presidência da República }\end{array}$ & $\begin{array}{l}\text { Assistir o Presidente da República, exercer a direção } \\
\text { superior da pasta, formular e implementar políticas e } \\
\text { diretrizes, prestar orientação, coordenação e supervisão } \\
\text { dos órgãos e entidades da administração federal na área } \\
\text { de sua competência; referendar os atos e decretos } \\
\text { assinados pelo Presidente da República; e expedir } \\
\text { instruções para a execução das leis, decretos e } \\
\text { regulamentos. }\end{array}$ \\
\hline $\begin{array}{l}\text { Natureza } \\
\text { Especial }\end{array}$ & $\begin{array}{l}\text { Secretário-executivo de ministério, } \\
\text { subchefes dos órgãos essenciais à } \\
\text { Presidência da República e dirigentes } \\
\text { da AGU }\end{array}$ & $\begin{array}{l}\text { Auxiliar o ministro de Estado na formulação de políticas } \\
\text { públicas, na definição de diretrizes e programas, na } \\
\text { supervisão e coordenação das secretarias integrantes da } \\
\text { estrutura do ministério ou secretaria especial e a } \\
\text { coordenação dos processos de gestão dos programas de } \\
\text { governo no plano plurianual, sob a responsabilidade do } \\
\text { ministério ou secretaria. }\end{array}$ \\
\hline DAS 101.6 & $\begin{array}{l}\text { Titulares das secretarias dos minis- } \\
\text { térios, subsecretário de órgão da PR e } \\
\text { dirigentes máximos de autarquias e } \\
\text { fundações. }\end{array}$ & $\begin{array}{l}\text { Planejamento, supervisão, coordenação, orientação e } \\
\text { controle da formulação de programas e normas da } \\
\text { administração pública. }\end{array}$ \\
\hline DAS 101.5 & $\begin{array}{l}\text { Chefe de gabinete de ministro, diretor } \\
\text { de departamento, secretário de } \\
\text { controle interno e subsecretário de } \\
\text { planejamento, orçamento e adminis- } \\
\text { tração, subchefes-adjuntos dos órgãos } \\
\text { essenciais da Presidência. }\end{array}$ & $\begin{array}{l}\text { Coordenação e articulação entre o comando político e a } \\
\text { área técnica, além da preparação de documentos e atos } \\
\text { para despacho das autoridades superiores. }\end{array}$ \\
\hline DAS 101.4 & $\begin{array}{l}\text { Coordenador-geral, chefe de gabinete } \\
\text { de autarquias e fundações, chefe de } \\
\text { assessoria de gabinete de ministro, } \\
\text { inclusive as jurídicas. }\end{array}$ & $\begin{array}{l}\text { Elaborar políticas públicas, justificar e fundamentar a } \\
\text { edição de ato normativo, além de assistir os ministros e } \\
\text { dirigentes máximos de autarquias e fundações. }\end{array}$ \\
\hline DAS 101.3 & Coordenador & \\
\hline DAS 101.2 & Chefe de divisão & \\
\hline DAS 101.1 & $\begin{array}{l}\text { Chefe de seção e assistência } \\
\text { intermediária }\end{array}$ & \\
\hline FG-1 & $\begin{array}{l}\text { Chefe de seção e assistência } \\
\text { intermediária }\end{array}$ & \\
\hline FG-2 & $\begin{array}{l}\text { Chefe de seção e assistência } \\
\text { intermediária }\end{array}$ & \\
\hline FG-3 & $\begin{array}{l}\text { Chefe de seção e assistência } \\
\text { intermediária }\end{array}$ & \\
\hline DAS 102.6 & Assessor especial & \\
\hline DAS 102.5 & Assessor especial de ministro de Estado & \\
\hline DAS 102.4 & Assessor & \\
\hline DAS 102.3 & Assessor técnico & \\
\hline
\end{tabular}

Fonte: Queiroz, 2009. 
Para cada ano, calculamos os quantitativos de funcionários ocupando cargos em DAS (variável EMP, para empregados); de funcionários que ocupavam cargo de DAS no ano anterior e mantiveram a mesma situação funcional (INA, para inalterada); que tiveram promoção ou rebaixamento de DAS (ALT, para alterada); que foram demitidos (DEM, para demitidos); e, finalmente, aqueles que foram contratados no ano corrente (CON, para contratados).

Essas variáveis foram calculadas tanto para o Executivo federal como um todo, como para cada ministério que o compõe. Apesar do quantitativo total de ocupantes de cargo de DAS (EMP) estar disponível a partir de 1999, as variáveis INA, ALT, CON e DEM somente puderam ser calculadas a partir de 2000, uma vez que seu cálculo depende da situação funcional no ano anterior. O Gráfico 1 apresenta os valores calculados dessas variáveis no caso do Executivo federal, em termos absolutos, enquanto o Gráfico 2 apresenta apenas as variáveis INA, ALT, CON e DEM como percentual do total de funcionários com DAS.

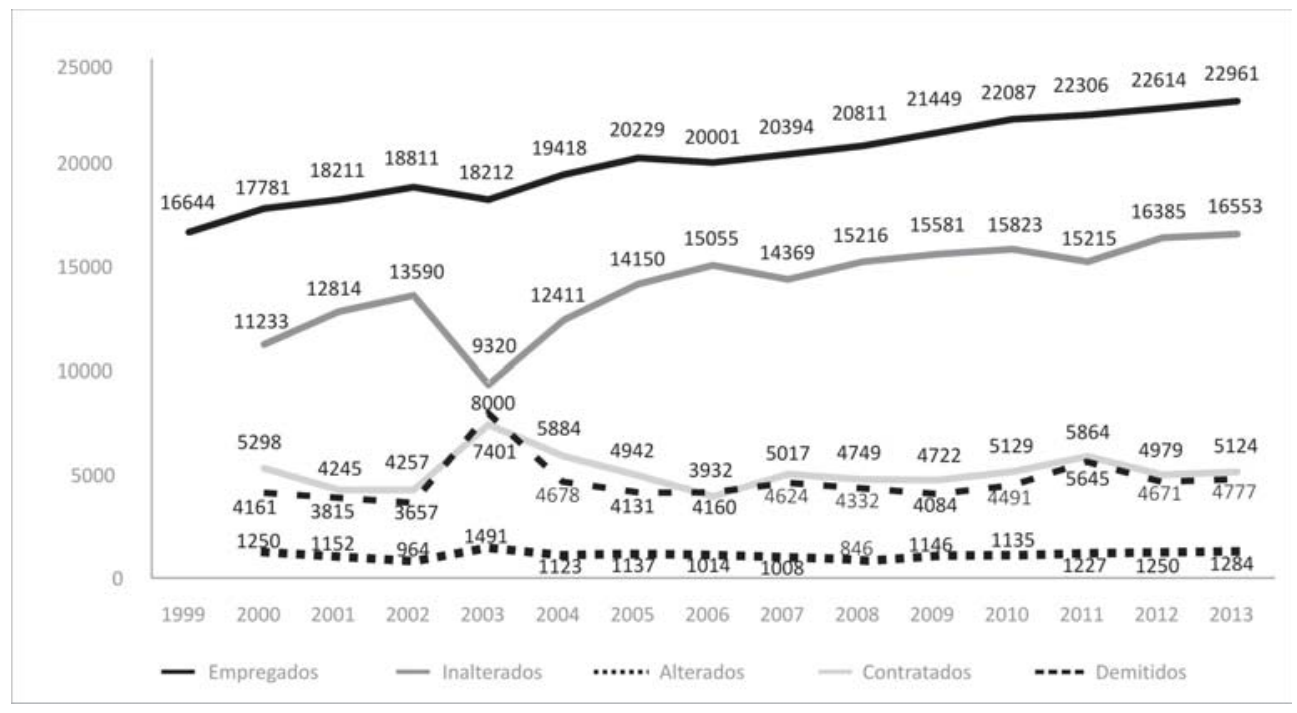

Empregados: Total de funcionários ocupando cargo de DAS.

Inalterados: Total de funcionários ocupando cargo de DAS que tiveram sua função inalterada em relação ao ano anterior.

Alterados: Total de funcionários ocupando cargo de DAS que tiveram sua função alterada em relação ao ano anterior, tendo sido promovidos ou rebaixados.

Contratados: Total de funcionários contratados no ano para ocupar cargo de DAS.

Demitidos: Total de funcionários que ocupavam cargo de DAS, mas foram demitidos no ano.

Fonte: Elaboração dos autores, com base em dados do Siape.

Gráfico 1: Evolução da ocupação de DAS no Executivo federal (1999-2013) 


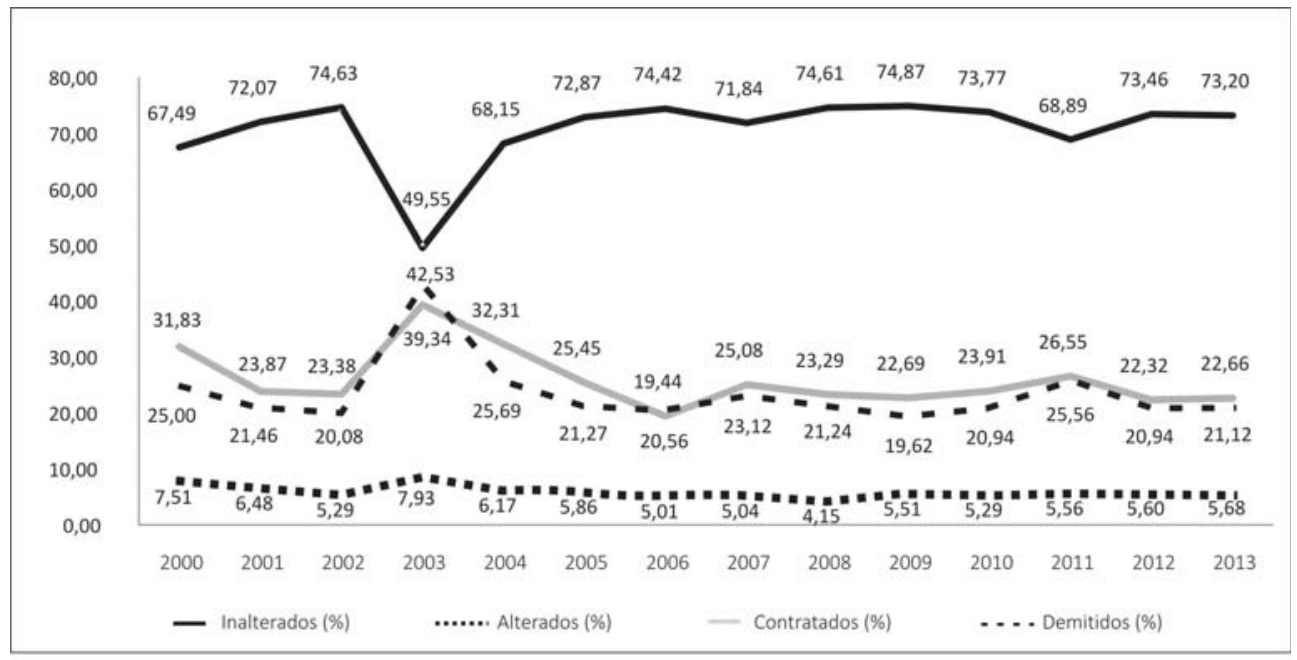

Inalterados (\%): percentual do total de funcionários ocupando cargo de DAS que tiveram sua função inalterada em relação ao ano anterior.

Alterados (\%): percentual do total de funcionários ocupando cargo de DAS que tiveram sua função alterada em relação ao ano anterior, tendo sido promovidos ou rebaixados.

Contratados (\%): percentual do total de funcionários contratados no ano para ocupar cargo de DAS.

Demitidos (\%): percentual do total de funcionários que ocupavam cargo de DAS, mas foram demitidos no ano.

Fonte: Elaboração dos autores, com base em dados do Siape.

\section{Gráfico 2: Percentual de alteração da ocupação de DAS no Executivo federal em relação ao total de empregados (1999-2013)}

Quanto ao critério de rotatividade usado, a área de Recursos Humanos define o conceito de rotatividade (turnover) como a relação entre o número de funcionários demitidos e o número de funcionários contratados. Ou seja, é um indicador da taxa de substituição de trabalhadores antigos por novos em um determinado período de tempo. De acordo com o relatório do Departamento Intersindical de Estatística e Estudos Socioeconômicos:

Conceitualmente, a rotatividade representa a substituição do ocupante de um posto de trabalho por outro, ou seja, a demissão seguida da admissão, em um posto específico, individual, ou em diversos postos, envolvendo vários trabalhadores. (DIEESE, 2011)

Chiavenato (2005) define rotatividade de pessoal como "o fluxo de entrada e saída de pessoas de uma organização, ou seja, as entradas para compensar as saídas das pessoas nas organizações. Em geral, cada desligamento quase sempre corresponde à admissão de um substituto". 
Tomando em conta as definições existentes de rotatividade, foram definidos três conceitos para o caso em análise, os cargos DAS, descritos a seguir.

i. Abordagem tradicional em Administração de Pessoal (ROT1): considera a média entre contratações e demissões. Trata-se da definição padrão de rotatividade da área de Recursos Humanos e pode ser calculada conforme a

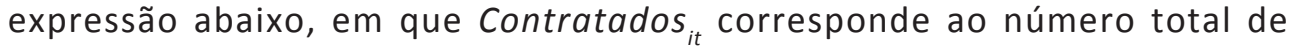
servidores novos contratados em cargos de DAS no ano $t$ pelo órgão $i$; Demitidos $_{\text {it }}$ corresponde ao número total de servidores demitidos de seus cargos de DAS no ano $t$ pelo órgão $i$; e Total ${ }_{i t-1}$ corresponde ao número total de servidores em cargos de DAS no órgão $i$ no início do ano $t$, ou seja, servidores em cargos de DAS do órgão $i$ ao final do ano $t-1$.

$$
\text { Rotatividade }_{1 \text { it }}=\frac{\frac{\text { Contratados }_{i t}+\text { Demitidos }_{\text {it }}}{2}}{\text { Total }_{i t-1}}
$$

ii. Abordagem abrangente inspirada no comércio internacional (ROT2): considera que a rotatividade deve ser definida não como a média, mas como a soma das demissões e contratações. Ademais, considera-se que a rotatividade também deve levar em conta as alterações de cargos ocorridas no ano, ou seja, deve-se contabilizar aqueles que mudaram de cargo DAS tendo sido promovidos ou rebaixados, e não apenas os contratados e demitidos. Pode-se então definir o segundo conceito de rotatividade conforme segue na equação (2) abaixo, em que

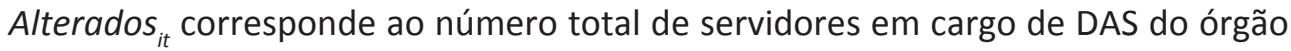
$i$ que tiveram seu cargo de DAS alterado ao longo do ano $t$.

$$
\text { Rotatividade }_{2 i t}=\frac{\text { Alterados }_{i t}+\text { Contratados }_{i t}+\text { Demitidos }_{i t}}{\text { Total }_{i t-1}}
$$

iii. Abordagem ampla baseada na permanência (ROT3): considera que a rotatividade deve ser definida em função de todas as alterações de cargos ocorridas no ano, ou seja, deve-se subtrair de $100 \%$ apenas o percentual de funcionários que não sofreram qualquer alteração em seus contratos. Pode-se então definir o terceiro conceito de rotatividade conforme segue na equação (3).

$$
\text { Rotatividade }_{3 i t}=\frac{\text { Total }_{i t-1}-\text { Inalterados }_{i t}}{\text { Total }_{i t-1}}
$$

O Gráfico 3 apresenta as rotatividades gerais no Executivo federal de 2000 a 2013 utilizando os três critérios citados. 


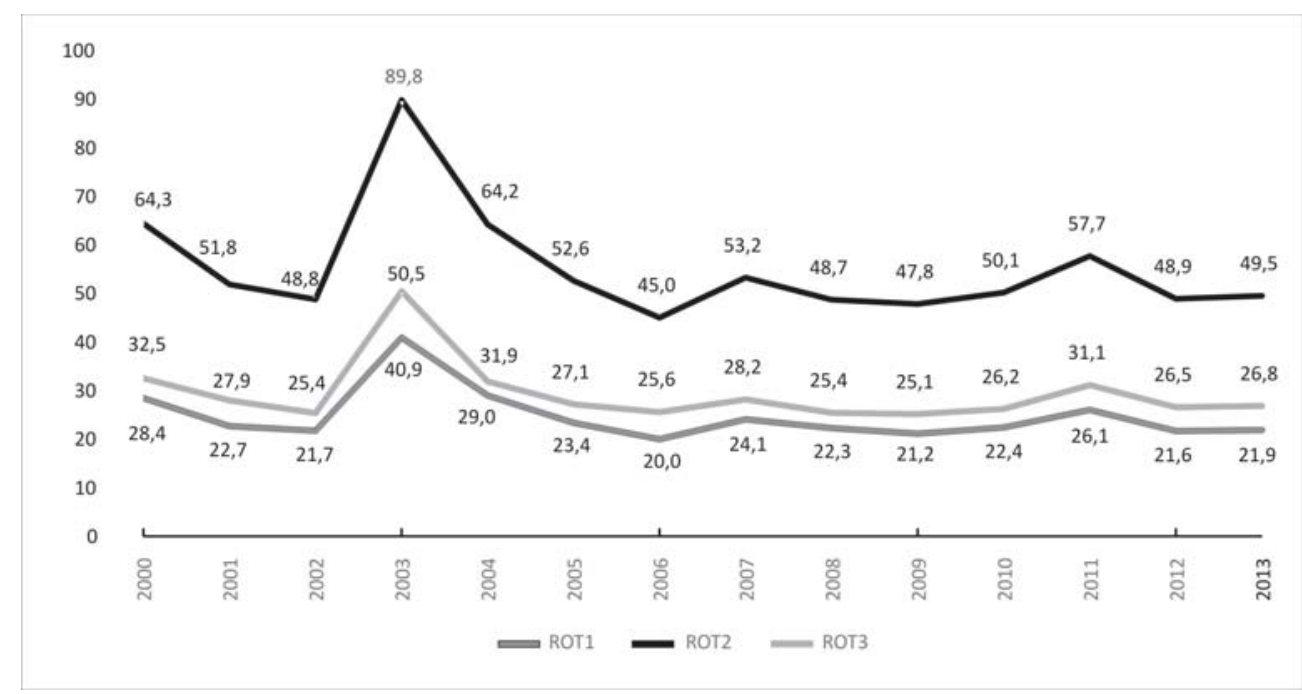

Nota: ROT1: Critério tradicional de rotatividade, 1.

ROT2: Critério abrangente de rotatividade, 2.

ROT3: Critério de rotatividade baseado na permanência, 3 .

Fonte: Siape. Elaboração dos autores.

Gráfico 3:Taxas anuais de rotatividade dos cargos DAS, utilizando três critérios (2000-2013) - (em \%)

É importante observar a relação entre as três definições.

Em primeiro lugar, o critério 1 gera valores mais baixos que o critério 2, pois não define como rotatividade as mudanças internas à instituição considerada, ou seja, as promoções e os rebaixamentos. Observe, ainda, que enquanto o critério 1 calcula uma média de demissões e contratações, o critério 2 soma essas duas variáveis (além das alterações). Trata-se de uma definição inspirada naquela usada em comércio internacional, em que se considera o volume de comércio entre dois países como a soma das exportações dos dois países, e não a média delas. Por essa razão, o critério 2 gerará sempre valores pelo menos duas vezes maiores que o critério 1 .

Em segundo lugar, como o denominador usado nas três definições corresponde ao total de empregados ao final do ano anterior, enquanto os numeradores se referem ao ano em questão, e, como na definição 2 se consideram também os demitidos, os critérios 2 e 3 não são equivalentes. De fato, é fácil mostrar que o critério 3 pode ser reescrito na forma a seguir:

$$
\text { Rotatividade }_{3 i t}=\frac{\frac{\text { Contratados }_{i t}+\text { Demitidos }_{i t}}{2}}{\text { Total }_{i t-1}}
$$


A expressão (3') deixa claro que, assim como o critério 1, o critério 3 gera valores menores que o critério 2 . O comportamento geral dos três índices é bastante semelhante, havendo mudanças apenas no nível, para o caso do critério 2. Os critérios 1 e 3 se configuram muito próximos.

Por fim, vale notar que o critério 3 não varia em função de novas contratações que resultem em ampliação do número de DAS. Por essa razão, o critério 3 reflete mais proximamente o conceito de rotatividade que desejamos estudar neste artigo, ou seja, as alterações associadas à substituição de pessoas no quadro de DAS, e não à ampliação do quadro de funcionários de um ministério. Se houve muita contratação em um ministério pelo fato de ter sido criado um novo órgão, por exemplo, não seria apropriado incluir essa contratação como rotatividade. Portanto, o critério 3 é mais robusto e, de fato, não considera essas contratações como rotatividade ${ }^{5}$. Por esses motivos, escolhemos como mais apropriada a terceira medida de rotatividade, ROT3, e a utilizamos nas análises a seguir.

\section{Rotatividade geral e por níveis hierárquicos}

Ao apresentar as taxas de rotatividade, estamos falando de um universo, atualmente, de aproximadamente 23 mil cargos. O Gráfico 4 indica o crescimento quase continuado desses cargos que, na série, foi de $38 \%$. Ao desagregarmos as taxas de crescimento, por níveis, pode-se ver - ainda no Gráfico 4 - que o crescimento mais expressivo ocorreu no quantitativo de cargos da hierarquia superior (DAS 4 a 6). A ampliação foi da ordem de 85\%, ao passo que nos DAS 1 a 3 o crescimento foi de $29 \%$.

O Gráfico 5 reapresenta as taxas de rotatividade médias do Gráfico 3, utilizandose apenas o critério da permanência. Na mudança do Governo FHC (PSDB) para o Governo Lula (PT), segundo esse critério (ROT3), a rotatividade chegou a $50 \%$ no primeiro ano de governo. Analogamente, a rotatividade chegou a $28 \%$ no primeiro ano do segundo mandato do Presidente Lula e 31\% no primeiro ano de mandato da Presidente Rousseff (PT). A maior taxa de rotatividade anual foi observada precisamente no primeiro ano do Governo Lula, enquanto a mais baixa ocorreu no penúltimo ano de seu governo. A média de rotatividade no período foi de

\footnotetext{
${ }^{5}$ Os autores agradecem a Christian Lehmann por enfatizar essa propriedade desejada do conceito ROT3 de rotatividade.
} 
aproximadamente $30 \%$, enquanto o desvio-padrão foi de quase $7 \%$. As mudanças acentuadas observadas no ano de 2003 parecem indicar a relevância da mudança partidária para explicar as substituições observadas nos quadros que ocupam os cargos em DAS, nos ministérios. Pode-se observar que, também no primeiro ano do Governo Rousseff, há elevação em relação à média do segundo mandato de Lula, embora menos expressiva. A mudança de presidente sem alteração do partido modera o grau de rotatividade - tomando-se como único parâmetro possível o ano de 2011.

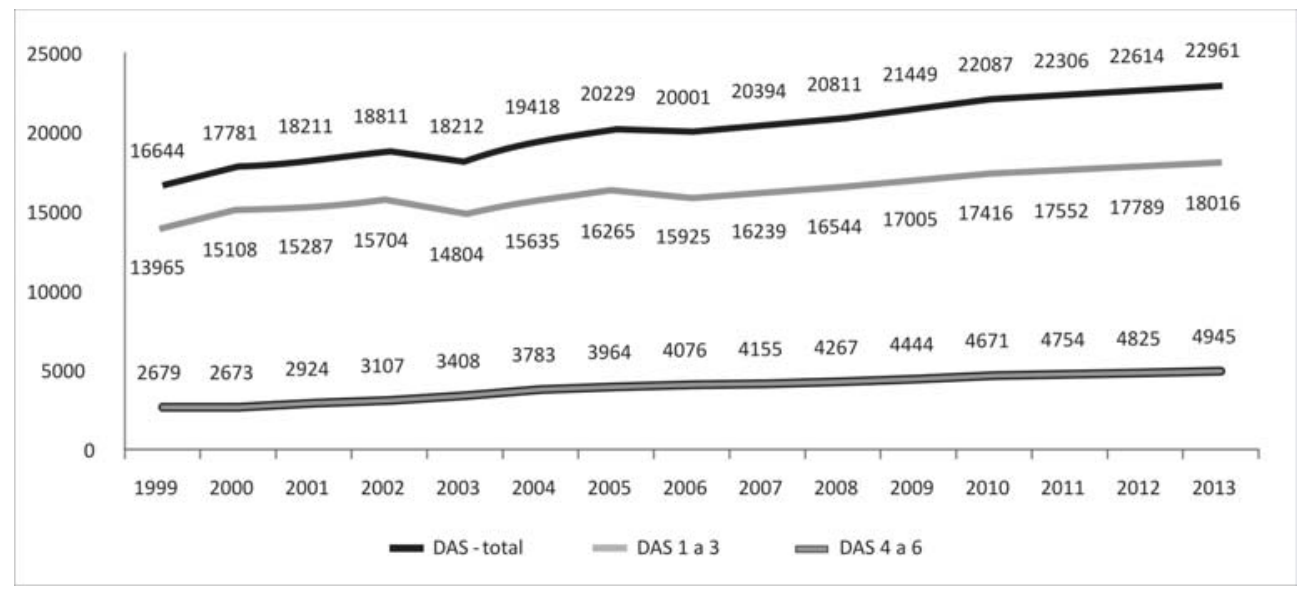

Fonte: Siape. Elaboração dos autores.

\section{Gráfico 4: Evolução no total de DAS, por ano e grupos hierárquicos (1999-2013)}

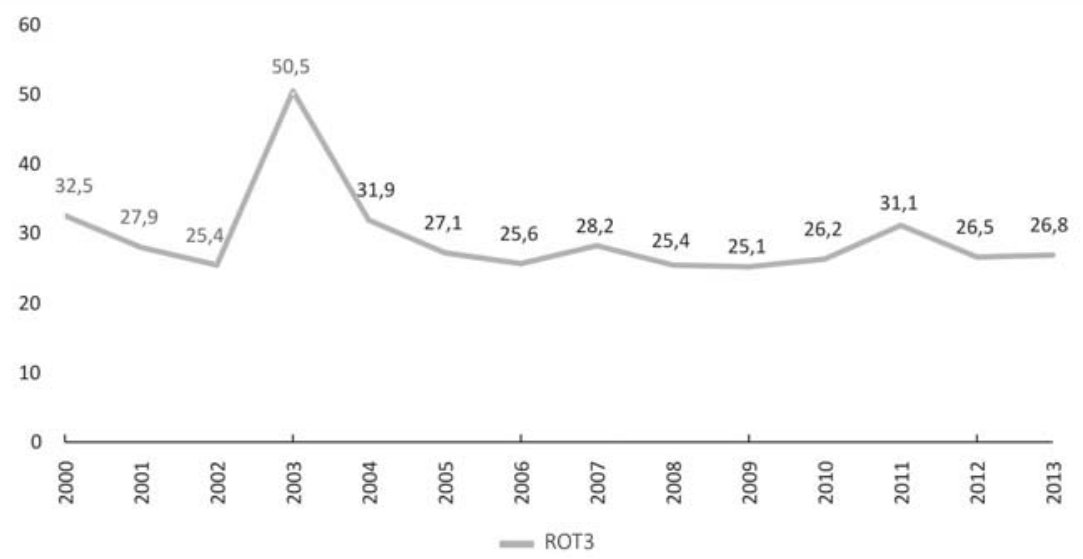

Fonte: Siape. Elaboração dos autores.

Gráfico 5: Variação anual das taxas de rotatividade dos cargos DAS (1999-2013) - (em \%) 
O Gráfico 6 apresenta a rotatividade medida para dois diferentes grupos, para todos os cargos DAS do governo, entre 2000 e 2012. O primeiro grupo, DAS 1 a 3, incorpora a rotatividade na ocupação de cargos em DAS nos níveis 1 , 2 e 3, os níveis mais baixos da categoria, enquanto o segundo grupo corresponde aos níveis mais elevados da hierarquia (DAS 4, 5 e 6). Observa-se maior rotatividade para cargos superiores, que têm maior poder político e administrativo (cf. Tabela 1). Na média, eles apresentam maior rotatividade que os demais (33,15\% contra $28,67 \%)$. Ademais, sua rotatividade tem desvio-padrão quase duas vezes maior que aquela dos cargos de níveis mais baixos $(11,57$ contra 6,02$)$. Os únicos anos em que houve inversão dessa tendência de maior rotatividade foram o último ano do primeiro mandato do Presidente Lula e o penúltimo ano de seu segundo mandato. A conexão entre poder político-administrativo e mudanças de governo é ainda mais visível nos momentos de mudança de governo. Vê-se que mesmo o Governo Rousseff, cujas taxas de rotatividade gerais foram mais moderadas que o Governo Lula, apresentou forte mudança quando restringimos a análise ao grupo de DAS 4 a 6. Em 2011, primeiro ano do mandato da presidente, a rotatividade para aquele grupo de cargos vai a $44 \%$, ultrapassando em quase 9 pontos percentuais a rotatividade de DAS no primeiro ano do segundo mandato de Lula.

A observação por cada um dos 6 níveis hierárquicos, retratada no Gráfico 7, reforça a percepção de que as mudanças mais acentuadas, em início de mandatos, têm forte correlação com o nível hierárquico do cargo. Nota-se, por exemplo, que

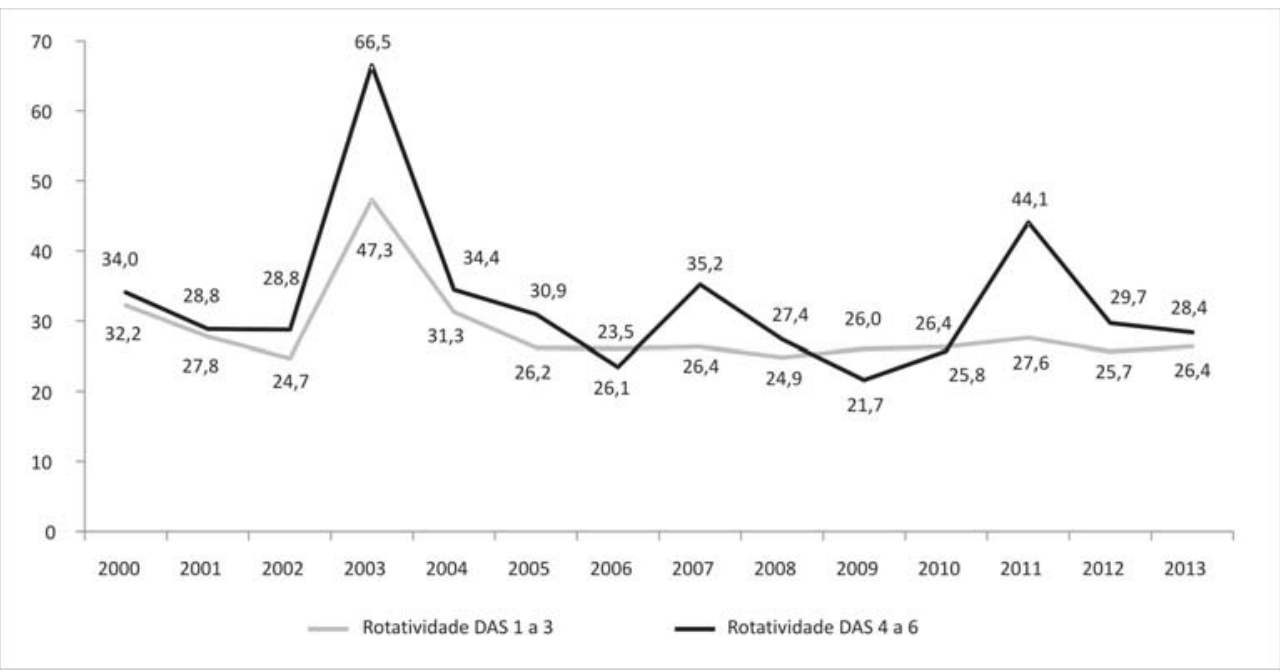

Fonte: Siape. Elaboração dos autores.

Gráfico 6: Variação anual na taxa de rotatividade dos cargos DAS, por grupos hierárquicos (1999-2014) - (em \%) 
a rotatividade foi quase total, atingindo o impressionante valor de 91,5\% no primeiro ano do Governo Lula, para os cargos de DAS 6. Curiosamente, parece haver uma inversão no penúltimo ano do segundo mandato do Governo Lula, em que a rotatividade em DAS 5 e 6 foi menor do que em DAS 1 e 2. Vale também notar que a variância da rotatividade aumenta quase que monotonicamente quando se vai de DAS 1 a DAS 6, sendo o desvio-padrão igual a 5,4 para a rotatividade nos cargos de DAS $1 ; 7,25$ nos cargos de DAS 2; 6,12 nos cargos de DAS 3; 10 nos cargos de DAS 4; 15,5 nos cargos de DAS 5; e, finalmente, impressionantes 19,73 nos cargos de DAS 6.

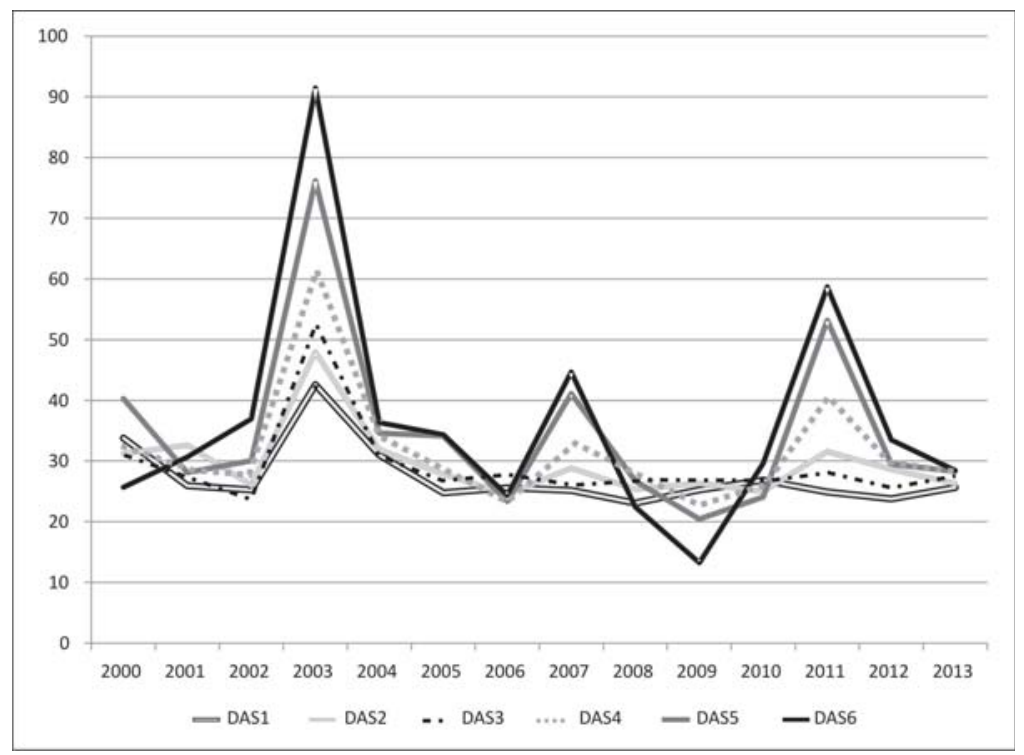

Fonte: Siape. Elaboração dos autores.

Gráfico 7: Rotatividade dos cargos DAS, por nível hierárquico (1999-2013) - (em \%)

\section{Rotatividade por origem administrativa}

A relevância atribuída à discussão sobre rotatividade nos cargos DAS decorre, em parte, de concepções distintas sobre os efeitos positivos ou negativos decorrentes do exercício do cargo por servidores oriundos do setor privado (e não público) ou público, em particular aqueles que integram as carreiras burocráticas dos respectivos órgãos. A esse respeito, é pertinente relembrar que, nos idos da Constituinte - no Decreto no 2.407/1987 - e, posteriormente, na Constituição Federal de 1988, havia o objetivo de reduzir radicalmente o sistema de provimento por meio de cargos em comissão baseados nas indicações de confiança, que seriam quase integralmente substituídos por funções destinadas aos funcionários das 
diferentes carreiras do serviço público. As funções de confiança deveriam se limitar aos cargos de natureza especial, chefes de gabinete e alguns assessores diretos. A ideia, contudo, não foi implementada (Graef, 2010; 2008).

Se, por um lado, alega-se que o recrutamento interno confere maior expertise, capacidade de planejamento do ciclo das policies (LEWIS, 2011; 2009; 2008) e menores incentivos para práticas corruptas (Meneguin; BugARIN, 2012), por outro, pode-se sustentar ser a seleção externa fonte de inovações em práticas administrativas e de redução da ineficiência no setor público (PACHECO, 2011; 2010, MARANTO, 1998). As posições, por si, sugerem a importância de observar a variação das taxas de rotatividade, distinguindo nomeados oriundos do serviço público e aqueles de fora da burocracia.

O Gráfico 8 apresenta, primeiro, a distribuição dos ocupantes de DAS por critérios de pertencimento ou não ao serviço público federal. Parece-nos expressiva a proporção de nomeados oriundos do próprio setor público, bem como a constância da distribuição ao longo da série. Entretanto, nos níveis superiores, a presença de servidores de carreira e de fora do serviço público é mais equilibrada. Só nos últimos quatro anos, os servidores de carreira são maioria nesses cargos.

Vale notar que o percentual de cargos do grupo DAS 4 a 6 ocupados por gestores provenientes do serviço público de carreira dobrou no período analisado, passando

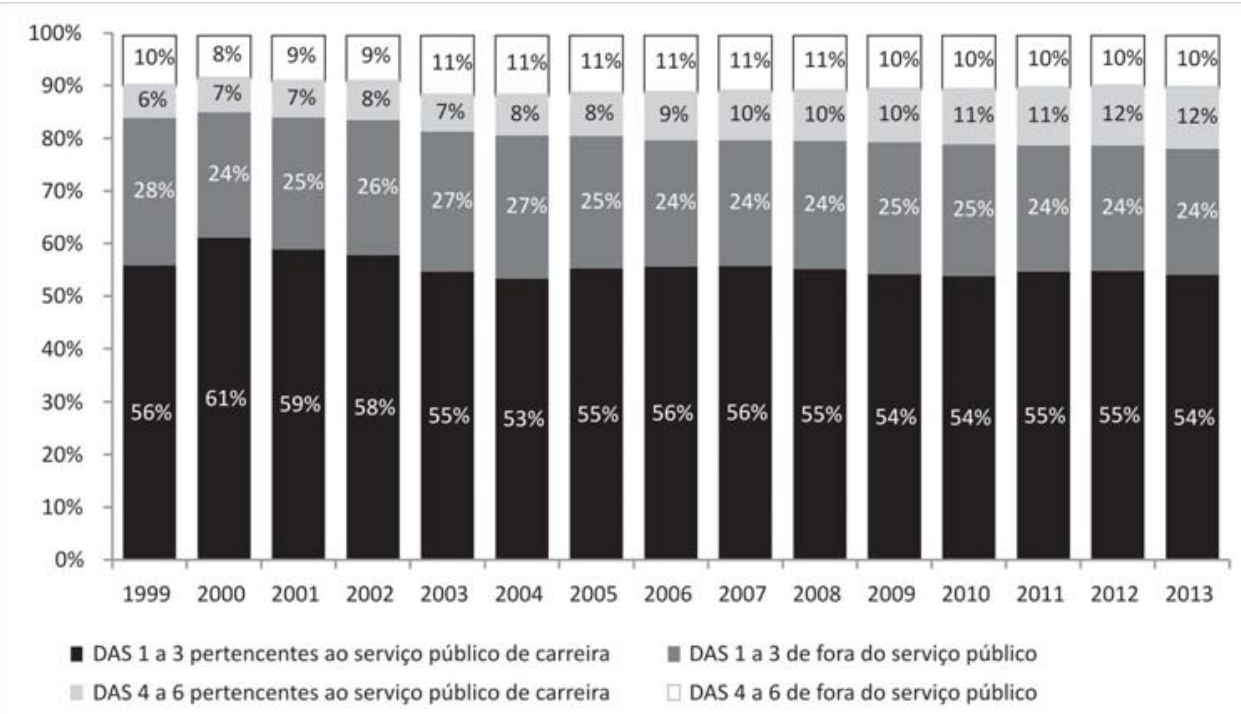

Fonte: Siape. Elaboração dos autores.

Gráfico 8: Proporção de ocupantes de cargos DAS, por grupos, pertencentes ao serviço público de carreira (1999-2013) - (em \%) 
de $6 \%$ para $12 \%$ do total de cargos DAS e de $40 \%$ para $54 \%$ do total de DAS desse grupo. As trajetórias de crescimento devem ser consideradas à luz do forte crescimento do número de cargos DAS desse grupo, que foi de $80 \%$, como indicou o Gráfico 4. A mudança sugere maior profissionalização do serviço público federal, que tem conseguido, por meio de suas carreiras, fornecer funcionários com competência para assumir cada vez maior número de cargos de DAS. A partir de 2009, os funcionários de carreira passaram a ocupar a maioria dos cargos de DAS tanto na categoria 1 a 3 , em que somam mais que o dobro do número de funcionários recrutados fora da carreira, como na categoria 4 a 6 , única categoria em que ainda se observa clara tendência de crescimento.

O Gráfico 9A e o 9B reportam a distribuição das taxas de rotatividade para nomeados oriundos de dentro e de fora das carreiras do serviço público para as hierarquias superiores (DAS 4 a 6 ) e inferiores (DAS 1 a 3), respectivamente ${ }^{6}$. Eles indicam, em primeiro lugar, um comportamento bastante semelhante das duas séries. No entanto, com exceção dos anos de 2008 e 2009 somente no caso do grupo DAS 1 a 3, a rotatividade é sempre maior nos cargos ocupados por servidores de fora da carreira. Em outras palavras, pode-se dizer que a carreira pública traz maior estabilidade na ocupação dos cargos de DAS. Ademais, ambos os gráficos, e de forma ainda mais contundente o Gráfico 9B, indicam uma diferença expressiva nas taxas de rotatividade no ano de 2003, que novamente é reveladora. Por ser o ano de mudança de partido no Executivo federal, a diferença parece expressar de forma mais clara o efeito da mudança de partido no governo sobre os cargos de livre provimento. A diferença, para maior, na rotatividade dos nomeados de fora do serviço público naquele ano - e posterior estabilidade - parece indicar as motivações partidárias e ideológicas das nomeações, e a maior força desses critérios sobre os quadros de fora das carreiras do serviço público. Em outros termos, os dados indicam de forma mais clara a natureza política da escolha dos superiores hierárquicos.

\footnotetext{
${ }^{6}$ Conforme os dados do Siape, servidores de carreira incluem "servidores ativos ou inativos, oriundos de órgão ou entidade de qualquer dos Poderes da União, dos Estados, do Distrito Federal e dos Municípios, suas empresas públicas e sociedades de economia mista, ocupante de cargo ou emprego permanente, inclusive militar das Forças Armadas, agregado ou inativo, e o militar do Distrito Federal." (Boletim Estatístico de Pessoal, 2013: 175)
} 


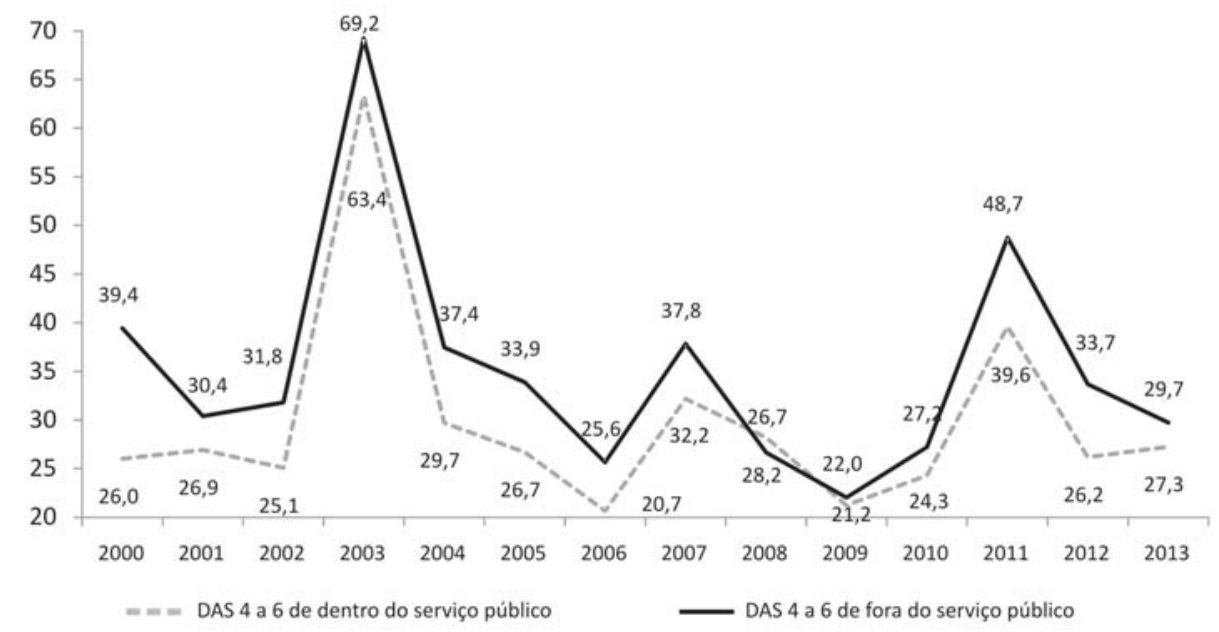

Fonte: Siape. Elaboração dos autores.

Gráfico 9A: Rotatividade anual do total de ocupantes de cargos DAS 4 a 6, conforme origem administrativa (1999-2013) - (em \%)

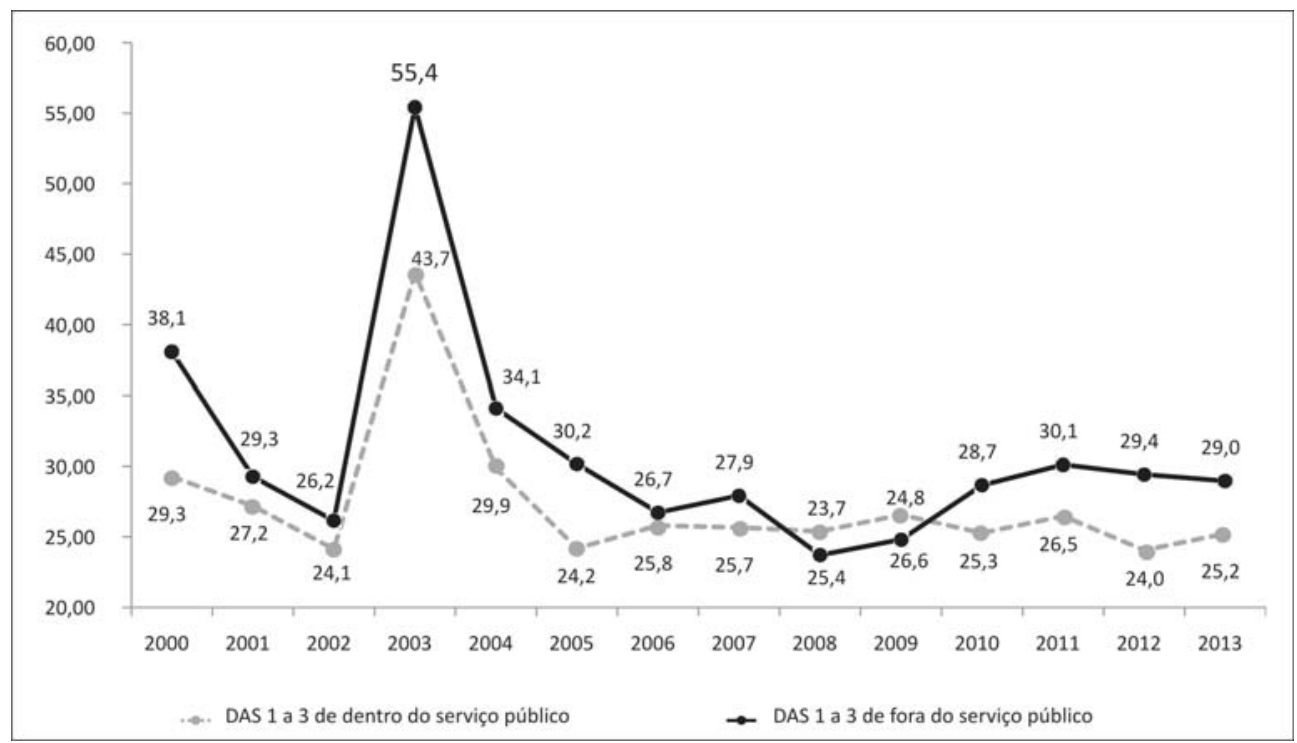

Fonte: Siape. Elaboração dos autores.

Gráfico 9B: Rotatividade anual do total de ocupantes de cargos DAS 1 a 3, conforme origem administrativa (1999-2013) - (em \%) 


\section{Rotatividade por órgãos governamentais}

Nesta seção, esboçamos o quadro geral da rotatividade em diferentes setores do governo.

Teoricamente, pode-se esperar variação nas taxas de rotatividade em função da natureza das políticas e áreas de governo. Setores do governo cujas políticas sejam mais complexas, e exijam conhecimento técnico mais detalhado, tenderiam à menor rotatividade, por exigirem maior continuidade das rotinas e especialistas para gerir os órgãos. A rotatividade pode também variar em função da combinação de outras propriedades dos órgãos governamentais, a exemplo da disponibilidade de funcionários de carreira e grau de institucionalização do órgão ou da política. Não é objetivo aqui testar estatisticamente essas variáveis e seus possíveis efeitos. Contudo, apresentamos a evolução das mudanças por grandes áreas de políticas.

O Gráfico 10 apresenta a rotatividade para DAS 4 a 6, em três ministérios responsáveis pelo gerenciamento da política econômica: Fazenda, Planejamento e Comércio Exterior. As variações seguem movimentos similares aos já identificados: forte mudança no primeiro ano do Governo Lula, cuja intensidade só é rivalizada, mas menor, no primeiro ano do Governo Rousseff. Observe que no Ministério do Planejamento, Orçamento e Gestão (MP) a rotatividade ultrapassa os $50 \%$ no primeiro ano do Governo Lula.

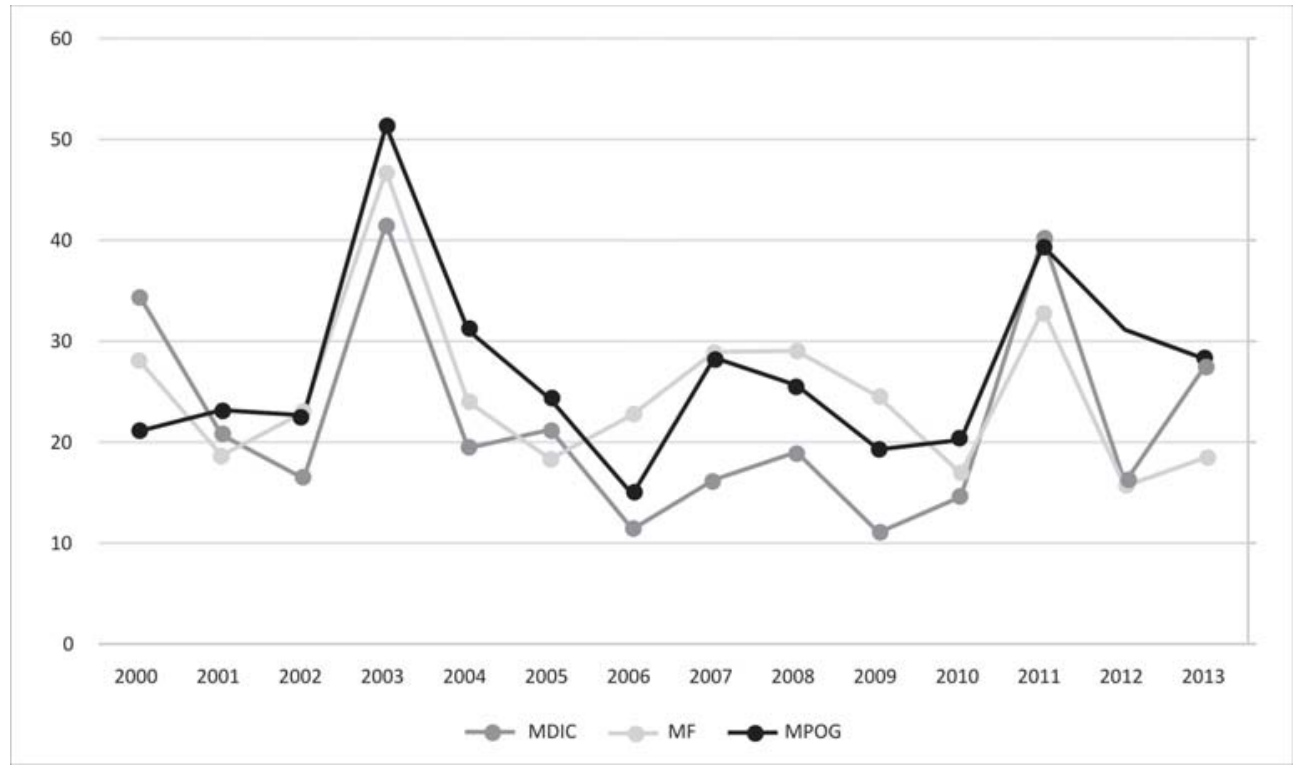

Fonte: Ipea. Elaboração dos autores.

Gráfico 10: Rotatividade anual dos ocupantes de cargos DAS 4 a 6, em ministérios selecionados da área econômica (1999-2013) - (em \%) 
Ao comparar as variações desse grupo com ministérios da área social típica aqui, Saúde, Educação e Cultura ${ }^{7}$-, verifica-se maior rotatividade nesses últimos. Como se pode ver no Gráfico 11, a variação é homóloga, mas de intensidade bem maior na área social. A rotatividade chega a quase $80 \%$ no Ministério da Educação (MEC) em 2003 e permanece acima de 70\% para os três ministérios nesse ano. No caso do Ministério da Saúde, parece haver um ciclo bianual na rotatividade, que se mostra mais baixa em ano eleitoral (nacional ou municipal) e mais elevada em ano pós-eleitoral, seguindo, portanto, bem de perto o ciclo eleitoral bianual. Vale comparar esse resultado com aquele do Ministério da Fazenda, que também apresenta claro ciclo eleitoral, contudo quadrienal.

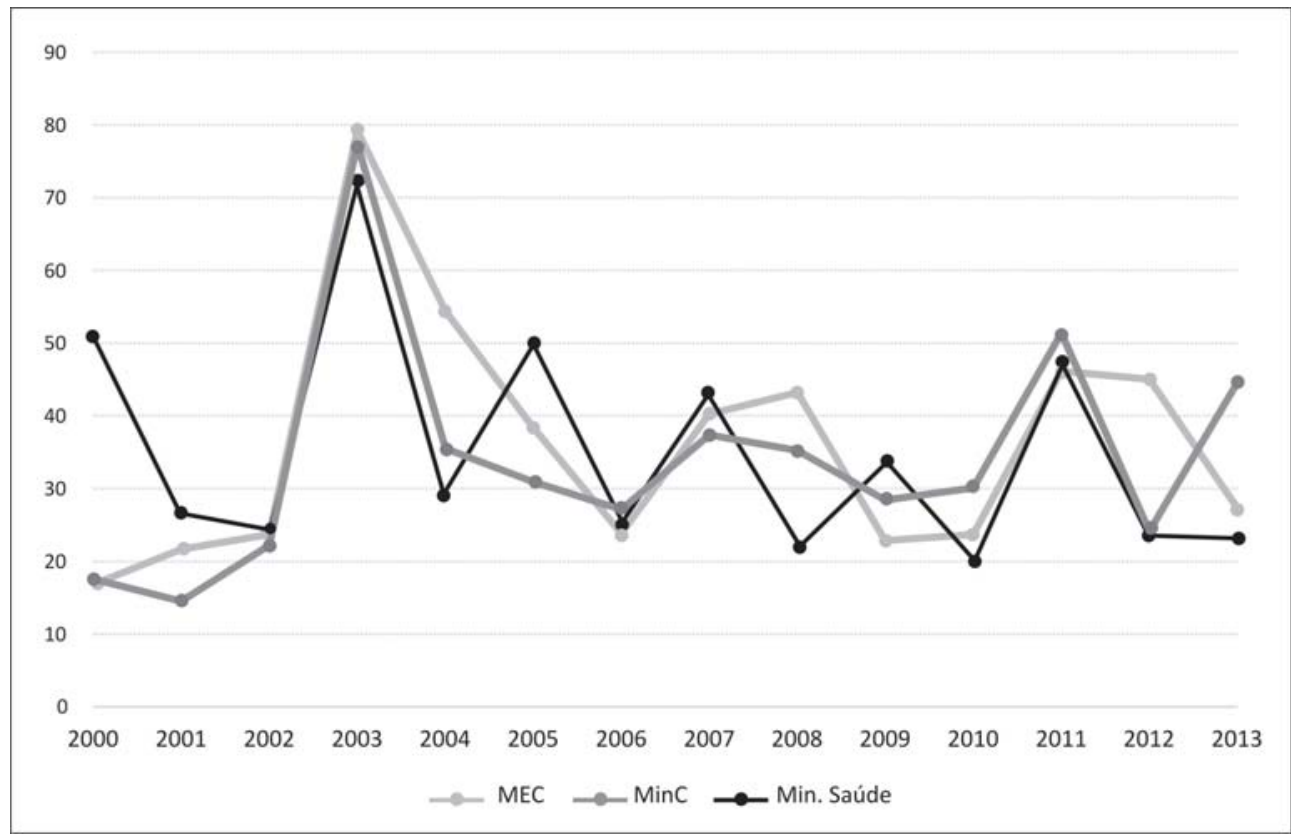

Fonte: Ipea. Elaboração dos autores.

Gráfico 11: Rotatividade anual dos ocupantes de cargos DAS 4 a 6, em ministérios selecionados da área social (1999-2013) - (em \%)

\footnotetext{
${ }^{7}$ Não incluímos o Ministério do Desenvolvimento Social e Combate à Fome por esse ter sido criado somente em 2003.
} 
O Gráfico 12 apresenta os dois grupos - econômicos e sociais -, ou seja, a evolução das rotatividades médias anuais dos DAS 4, 5 e 6, para os seis ministérios selecionados. Nele, observa-se nítida diferença entre os grupos. As transições de governo, por serem propícias à mudança nos quadros da administração, uma vez mais indicam de forma clara as diferenças. Pode-se observar, em particular na transição para o Governo Lula (2003), no primeiro ano de seu segundo mandato e no primeiro ano do Governo Rousseff (2011), que a rotatividade é superior nos ministérios sociais vis-à-vis os ministérios da área econômica. No final do Governo FHC, parece haver uma convergência nas duas médias para valores abaixo de $25 \%$.

Por fim, verifica-se no Gráfico 13 que, mesmo para o grupo DAS 1 a 3, a rotatividade média é menor em ministérios econômicos; apenas no ano de 2001, último ano do Governo FHC, as rotatividades foram similares.

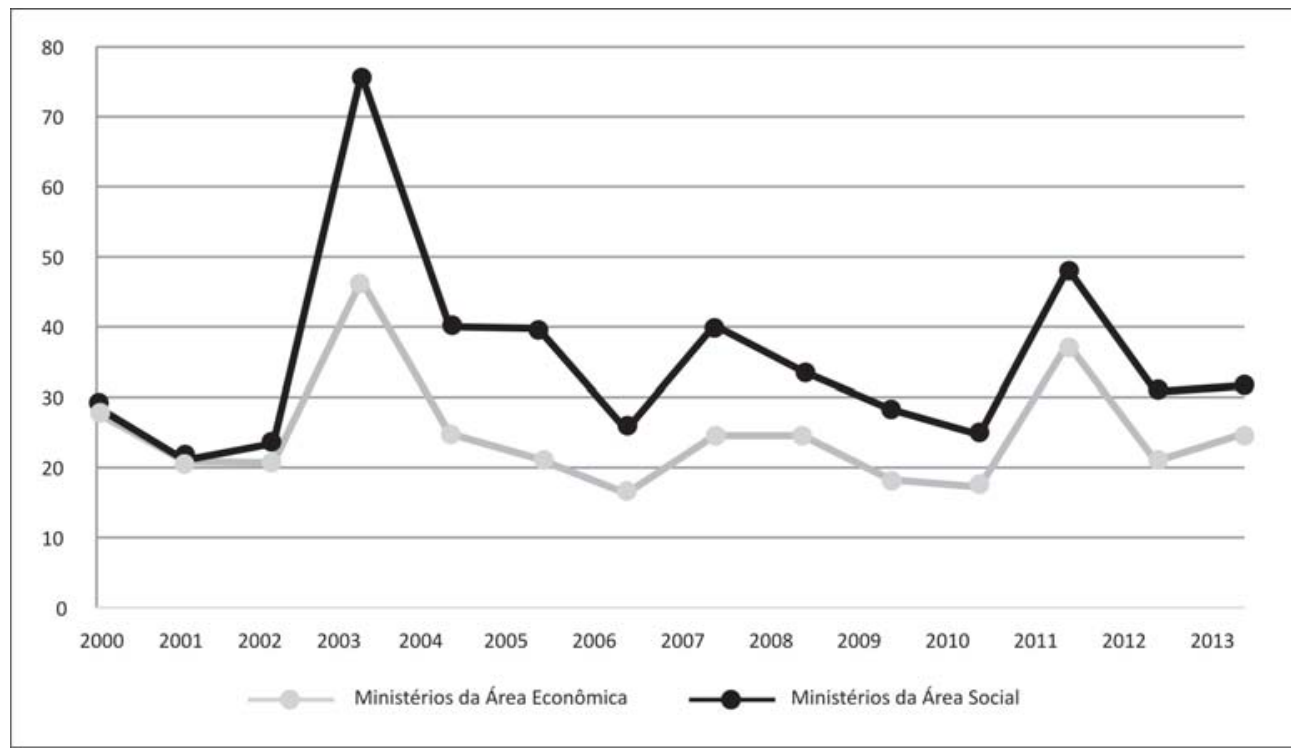

Fonte: Ipea. Elaboração dos autores.

Gráfico 12: Rotatividade média anual dos ocupantes de DAS 4 a 6 para grupos de ministérios selecionados (1999-2013) - (em \%)

\section{Conclusão}

Neste artigo apresentamos dados relativos à rotatividade dos cargos de livre nomeação (DAS) da administração pública federal e indicamos algumas das principais variações observadas entre governos, áreas de políticas e níveis dos cargos. Os dados ajudam a avançar na compreensão de nosso sistema de patronagem e de algumas de suas propriedades. Exploramos aqui uma delas, analisando a rotatividade dos cargos. 


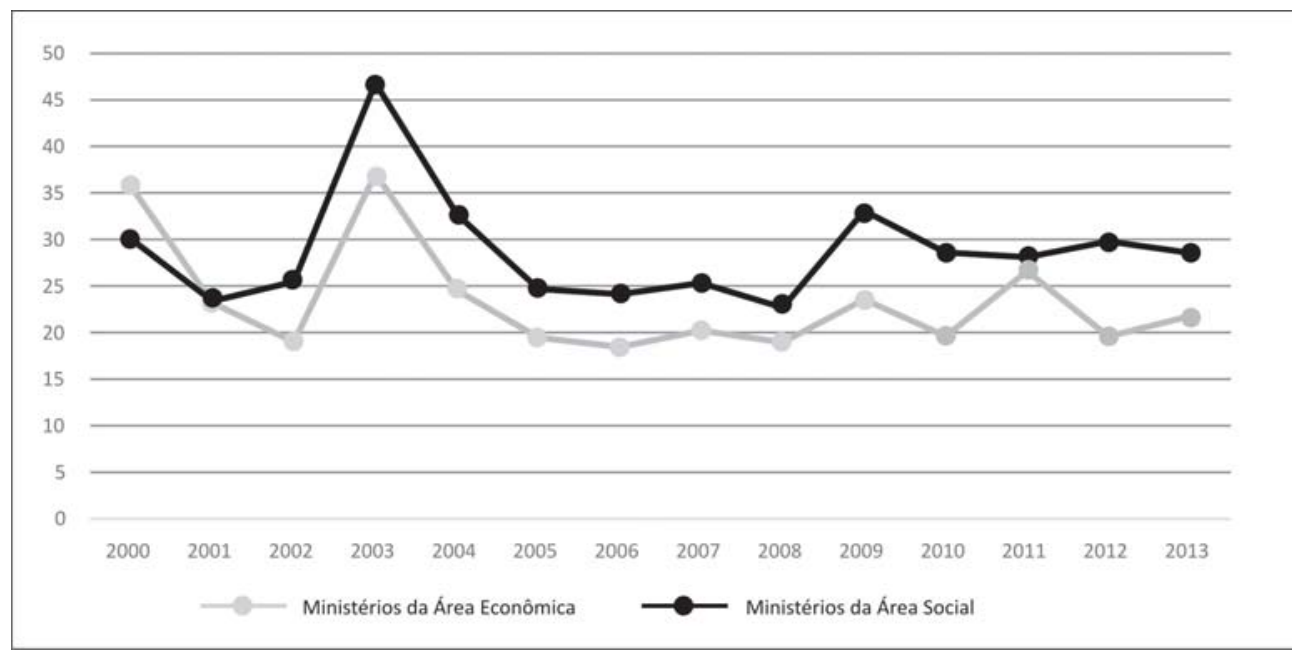

Fonte: Ipea. Elaboração dos autores.

Gráfico 13: Rotatividade média anual dos ocupantes de DAS 1 a 3 para grupos de ministérios selecionados (1999-2013) - (em \%)

Com base nessas variações, é possível, desde já, construir uma imagem mais adequada do processo de ocupação dos cargos.

Primeiro, indicamos que a rotatividade, como esperado, tem momentos de pico, que são os primeiros anos de governo dos presidentes, ao que se sucede uma tendência ao decréscimo nas taxas. A mudança reflete as alternâncias de poder dos ciclos eleitorais. A maior mudança observada - na série disponível - foi precisamente a chegada do PT ao poder federal, que representou uma mudança de $50 \%$ nos cargos DAS, em relação ao ano anterior. O resultado parece nos indicar a força da motivação partidária nesses momentos de mudança de poder. Será importante, em análises futuras, decompor outas motivações que se associam ao motivo partidário, para retratar de forma mais precisa outras variáveis importantes no processo de constituição da burocracia de confiança.

Também encontramos que são os cargos de maior hierarquia os mais sujeitos à rotatividade. A imagem segundo a qual os cargos inferiores, por serem menos valiosos no mercado político, são mais suscetíveis à distribuição personalista e apresentam mudança mais intensa não parece correta. Diferentes fatores contribuem para os resultados que apresentamos. O principal deles talvez seja a dificuldade de atrair para Brasília nomeados escolhidos em redes pessoais, devido aos custos dessa transferência. A isso é possível que se some a natureza dos próprios cargos que, ao pedir exercício de funções mais cotidianas e rotineiras voltadas para a gestão dos próprios órgãos, exijam ou permitam maior 
permanência dos servidores, a despeito de mudanças político-partidárias nos órgãos governamentais ou níveis superiores da burocracia política.

Encontramos ainda que, em geral, há maior rotatividade entre os ocupantes de cargos de DAS que não pertencem à carreira do serviço público. Esse resultado poderia apontar para uma melhor qualificação dos servidores de carreira, o que os manteria em seus cargos apesar das mudanças no comando político dos ministérios em que atuam.

Por fim, mostramos que há uma tendência de rotatividade menor em ministérios da área econômica, se comparada a ministérios da área social. Seria preciso verificar de forma mais detida as razões dessa diferença, mas espera-se que derivem da natureza das funções, que exigem graus de especialidade inibidores de rotatividades mais altas.

O presente trabalho apresenta uma exploração inicial na fascinante análise da rotatividade no serviço público federal e pode ser estendido em diversas direções.

Em primeiro lugar, os dados estilizados encontrados nos permitem tecer uma série de hipóteses a respeito dos fatores que condicionam a rotatividade dos cargos de DAS no País. Uma extensão natural deste trabalho é explicitar essas hipóteses e testá-las por meio de modelos econométricos.

Em seguida, os fatos estilizados permitem a construção de um modelo de economia política que tente explicitar os principais dilemas com os quais se defronta um ministro ao escolher gestores para ocupar cargos de DAS. Por um lado, o ministro procura gestores competentes para administrar as políticas públicas sob sua responsabilidade. Isso sugeriria uma menor rotatividade, uma vez que a experiência desempenha papel importante para uma gestão competente. Por outro lado, o ministro deseja manter assessores de sua inteira confiança. Essa última preocupação sugeriria maior rotatividade, uma vez que, quando muda o ministro, deveriam também mudar os quadros ocupando cargo em DAS. Finalmente, há um terceiro fator, associado ao nosso presidencialismo de coalizão, que reduziria a liberdade de escolha do ministro, devido aos acordos firmados para formar e manter a coalizão governamental. Um modelo teórico que incorpore esses trade-offs poderá lançar luz sobre os mecanismos que levam às variações das taxas de rotatividade observadas neste trabalho.

Essas extensões são apresentadas aqui como sugestão para pesquisas futuras. 


\section{Referências bibliográficas}

Brasil. Ministério do Planejamento, Orçamento e Gestão. Secretaria de Gestão Pública (Segep). Boletim estatístico de pessoal e informações organizacionais. v. 18, n. 211. Brasília: MP, 2013.

Chiavenato, Idalberto. Gestão de pessoas. 2a edição. Rio de Janeiro: Elsevier, 2005. Departamento Intersindical de Estatística e Estudos Socioeconômicos (Dieese). Rotatividade $e$ flexibilidade no Mercado de trabalho. São Paulo: Dieese, 2011.

Graef, Aldino. Origens e fundamentos da carreira de gestor governamental. Res-Pvblica: Revista de Políticas Públicas e Gestão Governamental , Brasília: Anesp, v. 9, n. 1, p. 7-24, jan./jun. 2010.

Cargos em comissão e funções de confiança: diferenças conceituais

e práticas. ResPvblica: Revista de Políticas Públicas e Gestão Governamental , Brasília: Anesp, v. 7, n. 2, p. 61-72, jul./dez. 2008.

GrindLe, Merilee S. Jobs for the boys: patronage and the State in comparative perspective. Cambridge: Harvard University Press, 2012.

QueIroz, Antônio Augusto de. Por dentro do governo: como funciona a máquina pública. Brasília: Diap, 2009. (Série Estudos politicos)

LewIS, David. Presidential appointments and personnel. Annual Review of Political Science, v. 14, p. 47-66, jun. 2011.

LeWIS, David. Revisiting the Administrative Presidency: Policy, Patronage, and Agency Competence. Presidential Studies Quarterly, v. 39, 1, p. 60-73, 2009.

LEWIS, David. The politics of presidential appointments: political control and bureaucratic performance. Princeton: Princeton University Press, 2008.

LAMEIRÃo, Camila. A ordenação dos cargos de direção e assessoramento superiores (DAS) como estratégia para o fortalecimento institucional e decisório do presidente da República. In: CARDoso JúnIOR, J. C.; PIRES, Roberto. (Org.). Gestão pública e desenvolvimento: desafios e perspectivas. Brasília: Ipea, 2011.

Meneguin, Fernando; Bugarin, Maurício. O papel das instituições nos incentivos para a gestão pública. Texto para discussão n. 118. Brasília: Senado Federal, 2012.

Moranto, Robert. Thinking the unthinkable in public administration: a case for spoils in the federal bureaucracy. Administration and Society, v. 29, n. 6, p. 623642, jan., 1998.

PACHECO, Regina. Critérios de nomeação para cargos de direção no setor público. Desigualdade \& Diversidade: Revista de Ciências Sociais da PUC-Rio , n. 9, p. 21-30, jul./dez. 2011. Disponível em: <http://desigualdadediversidade.soc.puc-rio.br/ cgi/cgilua.exe/sys/start.htm?tpl=home>. Acesso em: out. 2014.

PACHECO, Regina. Profissionalização, mérito e proteção da burocracia no Brasil. In: Loureiro, Maria; Abrucio, Fernando; Pacheco, Regina. (Orgs). Burocracia e política no Brasil: desafios para o Estado democrático no século XXI. São Paulo: FGV, 2010. 
Peters, Guy. La politica de la burocracia. Ciudad de Mexico: Fondo de Cultura Económica, 1999.

Peters, Guy; Pierre, Jon. The politicization of the civil service in comparative perspective. Londres: Routledge, 2004.

Praça, Sérgio; Freitas, Andréa; Hoepers, Bruno. Rotatividade dos servidores de confiança no governo federal brasileiro (2010-2011). Novos Estudos, Cebrap, São Paulo, v. 94, p. 94-107, nov. 2012.

\section{Felix Lopez}

Doutor em Sociologia e Antropologia pela Universidade Federal do Rio de Janeiro e Técnico de Planejamento e Pesquisa do Instituo de Pesquisas Econômicas Aplicadas (Ipea). Contato: felix.lopez@ipea.gov.br

Maurício Bugarin

PhD in Economics pela University of Illinois, Estados Unidos (1997), Professor Titular do Departamento de Economia da Universidade de Brasília e líder do Economics and Politics Research Group (CNPq). Contato: bugarin.mauricio@gmail.com

Karina Bugarin

Master in Economics pela University of Tsukuba, Japão (2011) e pesquisadora do Economics and Politics Research Group (CNPq). Contato: sayuribugarin@gmail.com 
RSP 